\title{
Erratum to: Regional hydrological cycle changes in response to an ambitious mitigation scenario
}

\author{
H. Huebener • M. G. Sanderson • I. Höschel • J. Körper • T. C. Johns • \\ J.-F. Royer • E. Roeckner • E. Manzini • J.-L. Dufresne • O. H. Otterå • \\ J. Tjiputra • D. Salas y Melia • M. Giorgetta • S. Denvil • P. G. Fogli
}

Published online: 6 September 2013

(C) Springer Science+Business Media Dordrecht 2013

\section{Erratum to: Climatic Change, Volume 120, Issue 1 (2013), Page 389-403 DOI 10.1007/s10584-013-0829-x}

Unfortunately, in the aforementioned contribution, Fig. 5 (Monthly multi-model (mean and range) precipitation change (mm/day) for 2080-2099 minus 1980-1999 averaged over the 26 regions, E1 (black) and A1B (grey) scenarios) contains an error. For two of the contributing models (ECHAM5-C and INGVCE) the evapotranspiration data had the wrong sign, leading to an opposing annual cycle in these models compared to the other models. The

The online version of the original article can be found at http://dx.doi.org/10.1007/s10584-013-0829-x.

H. Huebener $(\bowtie)$

Hessian Agency for Environment and Geology, Rheingaustraße 186, 65203 Wiesbaden, Germany e-mail: heike.huebener@hlug.hessen.de

M. G. Sanderson • T. C. Johns

Met Office Hadley Centre, Fitzroy Road, Exeter EX1 3PB, UK

I. Höschel · J. Körper

Freie Universität Berlin, Institut für Meteorologie, Carl-Heinrich-Becker-Weg 6-10, 12165 Berlin, Germany

J.-F. Royer • D. Salas y Melia

Centre National de Recherches Météorologiques-Groupe d'Etude de l'Atmosphère Météorologique (CNRM-GAME Meteo-France CNRS), 42 Avenue G. Coriolis, 31057 Toulouse, France

E. Roeckner $\cdot$ M. Giorgetta

Max Planck Institute for Meteorology, Bundesstrasse 53, 20146 Hamburg, Germany

E. Manzini

Istituto Nazionale di Geofisica e Vulcanologia, Bologna, Italy

E. Manzini • P. G. Fogli

Centro EuroMediterraneo per i Cambiamenti Climatici, Bologna, Italy

J.-L. Dufresne $\cdot$ S. Denvil

CNRS et Université Pierre et Marie Curie,

LMD/IPSL, 4 place Jussieu, 75252 Paris Cédex 05, France 

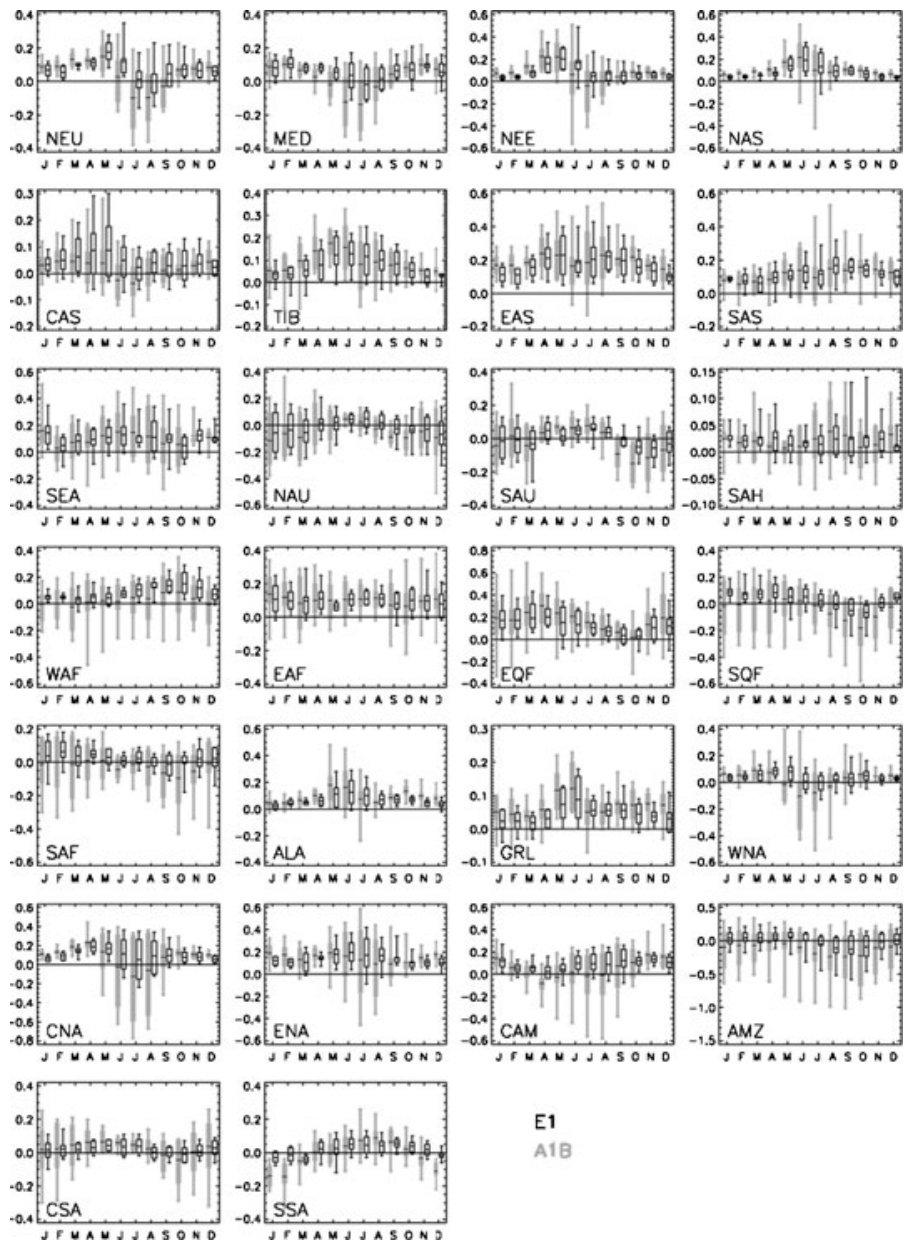

E1

A1B

Fig. 5 Monthly multi-model (mean and range) precipitation change (mm/day) for 2080-2099 minus 19801999 averaged over the 26 regions, E1 (black) and A1B (grey) scenarios. Boxes: 25-75\%, horizontal lines: mean value, whiskers: max. and min. Note the different scaling of the y-axis for some regions

O. H. Otterå

Nansen Environmental and Remote Sensing Center, Thormøhlensgt. 47, 5006 Bergen, Norway

O. H. Otterå • J. Tjiputra

Bjerknes Centre for Climate Research, Allegt. 55, 5007 Bergen, Norway

J. Tjiputra

Uni Climate, Uni Research, Allegt. 55, 5007 Bergen, Norway

Present Address:

E. Manzini

Max Planck Institute for Meteorology, Bundesstrasse 53, 20146 Hamburg, Germany

Present Address:

O. H. Otterå

Uni Climate, Uni Research, Allegt. 55, 5007 Bergen, Norway 
corrected Fig. 5 is presented here. It can be seen that the annual cycles of the climate change signals in evapotranspiration in the two scenarios agree much better between the different models than previously estimated. The general picture clearly underscores the findings from the preceding Figs. 3 and 4 that the climate change signals are much reduced under the E1 scenario compared to the A1B scenario. This is true for the ensemble properties (means, percentiles, and extremes) as shown here in the updated Fig. 5 as well as in the individual model results displayed in the electronic supplement material in Figure S6. 